\title{
Perfil de sujeitos com transtornos dos tecidos moles atendidos em um serviço de saúde do trabalhador $\mathrm{e}$ as $\mathrm{LER}^{-\mathrm{DORT}}{ }^{\mathbf{1}}$
}

\author{
Camila de Freitas ${ }^{a}$, Maria do Carmo Baracho de Alencar ${ }^{a}$, \\ Lucy Vitale Lopes ${ }^{\mathrm{b}}$, Felipe Granado Souza ${ }^{\mathrm{a}}$ \\ anniversidade Federal de São Paulo - UNIFESP, Santos, SP, Brasil. \\ ${ }^{\mathrm{b}}$ Centro de Referência em Saúde do Trabalhador - CEREST, Santos, SP, Brasil.
}

\begin{abstract}
Resumo: Objetivo: Investigar o perfil de sujeitos com transtornos dos tecidos moles atendidos no Centro de Referência em Saúde do Trabalhador-CEREST, Santos-SP, em 2010, e os benefícios previdenciários concedidos. Materiais e Métodos: Análise de prontuários de sujeitos atendidos em 2010, levantando os dados: gênero, idade, profissão, diagnósticos clínicos, queixas clínicas, situação de afastamento, entre outros. Os diagnósticos clínicos foram categorizados conforme a Classificação Internacional de Doenças CID-10 e selecionados os sujeitos com transtornos dos tecidos moles, bem como registrados diagnósticos relacionados a transtornos mentais. Os dados foram registrados no Programa Microsoft Excel e foi utilizado o sistema estatístico R Development Core Team ${ }^{\circledR}$. Resultados: Dos 206 prontuários, 18,0\% ( $\mathrm{n}=37$ ) tinham diagnóstico entre transtornos dos tecidos moles, sendo 81,1\% do gênero feminino e 18,9\% do masculino, idade média de 43,24 anos ( $\mathrm{DP}=8,76)$. A faixa etária mais acometida esteve entre 31 e 50 anos (70,2\%). Entre as profissões mais acometidas estavam: auxiliares de limpeza, auxiliares de serviços gerais e bancários. Os diagnósticos clínicos mais prevalentes foram: sinovites e tenossinovites, bursite de ombro e síndrome do manguito rotador, sendo que 62,2\% tinham mais de um diagnóstico clínico. Dos sujeitos, 13,5\% tinham também transtornos mentais. Houve associação entre situação de afastamento do trabalho e diagnóstico clínico estabelecido para transtornos dos tecidos moles $(\mathrm{p}=0,032)$. Dos dados obtidos apenas $13,5 \%$ conseguiram comprovar o nexo causal com o trabalho.Conclusões: O perfil geral do trabalhador foi obtido: prevalência em mulheres, acometimentos em faixa etária produtiva, dificuldade em obter o nexo causal com o trabalho e necessidade de intervenções interdisciplinares.
\end{abstract}

Palavras-chave: Transtornos Traumáticos Repetitivos, Saúde Ocupacional, Licença Médica.

\section{Profile of the subjects with soft tissue injuries attended at an occupational health service and the RSI}

\begin{abstract}
Aim: To investigate the profile of subjects with soft tissue injuries attended at the Reference Center of Occupational Health - CEREST in the municipality of Santos, Sao Paulo state, in 2010, and the social insurance benefits granted.Materials and Methods: Analysis of medical records of the subjects assisted at CEREST in 2010, surveying data on gender, age, occupation, clinical diagnostics, clinical complaints, retirement, etc. The clinical diagnostics were categorized according to the International Classification of Diseases - ICD-10, subjects with soft tissue injuries were selected, and the diagnostics related to mental health disorders were registered. Data were recorded in Microsoft Excel spreadsheet and analyzed using statistical software R Development Core Team ${ }^{\circledR}$.Results: Of the 206 medical records analyzed, $18.0 \%(\mathrm{n}=37)$ showed soft tissue injuries, $81.1 \%$ were female and $18.9 \%$ were male, and the subjects' mean age was 43.24 years $(\mathrm{SD}=8.76)$. Subjects between 31 and 50 years old $(70.2 \%)$ were
\end{abstract}

Autor para correspondência: Maria do Carmo Baracho de Alencar, Universidade Federal de São Paulo, Rua Silva Jardim, 136, Vila Mathias, CEP 11015020, Santos, SP, Brasil, e-mail: belinha.alencar1@gmail.com; alencar@unifesp.br

Recebido em Maio 31, 2013; $1^{\text {a }}$ Revisão em Out. 4, 2013; Aceito em Out. 15, 2013. 
the most affected. The most affected occupations were cleaners, general service workers, and bank clerks. The most prevalent clinical diagnoses were synovitis and tenosynovitis, shoulder bursitis, and rotator cuff syndrome, with $62.2 \%$ of the subjects presenting more than one clinical diagnosis. $13.5 \%$ of the subjects also presented mental disorders. Association between retirement from work and the presence of soft tissue injury was observed $(p=0.032)$. Only $13.5 \%$ of the diagnoses had some association with the work conditions.Conclusions: The general profile of the workers with soft tissue injuries was obtained: prevalence in women, diseases manifested in productive age, difficulty of association with work conditions, need for interdisciplinary interventions.

Keywords: Repetitive Strain Injury, Occupational Health, Sick Leave.

\section{Introdução}

No Brasil, as doenças ocupacionais vêm crescendo do ponto de vista da saúde coletiva causando, além de gastos financeiros para o Estado, enormes dificuldades sociais (GUTTERRES; BARFKNECHT, 2005). As doenças do sistema osteomuscular estão entre as principais causas de benefícios concedidos junto ao Instituto Nacional do Seguro Social - INSS (SOUZA et al., 2008; ALMEIDA; BARBOSA-BRANCO, 2011).

Segundo Salim (2003), ocorreu um forte crescimento das doenças relacionadas ao trabalho durante toda a década de 1990, relacionando-as às recentes mudanças na organização do trabalho, em que as lesões por esforços repetitivos - LER ou distúrbios osteomusculares relacionados ao trabalho - DORT afiguram-se como casos emblemáticos. A causa mais aparente do explosivo crescimento de LER está relacionada à incorporação das tecnologias de automação, colocando a produtividade em patamares mais elevados (RIBEIRO, 1997). Segundo esse autor, o esforço físico exigido pela automação é de outra natureza, ainda que continue comprometendo de muitas maneiras as várias estruturas musculoesqueléticas dos membros superiores, caracterizando-se em geral por um esforço leve e por isso capaz de ser repetido em alta velocidade pelas máos e dedos, ao mesmo tempo em que cobra uma postura estática dos segmentos corporais restantes.

As LER/DORT correspondem a um conjunto de afecçóes relacionadas às atividades laborativas que acometem músculos, fáscias musculares, tendóes, ligamentos, articulaçóes, nervos, vasos sanguíneos e tegumento (YENG et al., 2001). As LER/DORT têm o aparecimento e evolução de caráter insidioso (BRASIL, 2006). Para Rio (1998), há quadros clínicos específicos bem diagnosticados, facilitando a abordagem terapêutica, e há quadros clínicos inespecíficos de difícil diagnóstico e que não apresentam sinais evidentes, acompanhados com frequência de fatores psicossociais importantes no trabalho e fora dele.

A etiologia das LER/DORT é multifatorial e Chiavegato Filho e Pereira Junior (2004) referem o envolvimento de aspectos sociológicos, psicológicos e biológicos que interagem entre si. A LER/DORT pode atingir tanto trabalhadores em início de carreira quanto aqueles com muitos anos de trabalho no mesmo posto ou mesma função, em todos os ramos da economia: indústria, comércio e serviços, em diferentes níveis de escolaridade e diferentes cargos profissionais, tais como enfermeiras, açougueiros, operários, entre outros (NEVES, 2006). As LER/DORT têm acometido homens e mulheres em plena fase produtiva e têm causado inúmeros afastamentos do trabalho, cuja quase totalidade evolui para incapacidade parcial e, em alguns casos, para incapacidade permanente (BUCKLE, 2005). Segundo Crook e Moldofsky (1995), embora alguns estudos tragam bons prognósticos para alguns casos, as lesóes musculoesqueléticas consomem recursos consideráveis em atendimentos médicos, absenteísmo no trabalho e benefícios previdenciários.

As repercussões biopsicossociais dos DORT são inúmeras, pois causam dor crônica, incapacidade física, impactos legais, sociais, econômicos e psicológicos que requerem, entre outros, enfoque amplo e multidimensional (LIN et al., 2001). Segundo Wadell (2006), em casos de cronicidade e incapacidade há extensa evidência clínica que as condições de saúde dependem de aspectos psicossociais. Esses aspectos ressaltariam a necessidade de intervençóes reabilitadoras com equipes interdisciplinares e multiprofissionais junto aos casos crônicos de LER/DORT.

Estudos evidenciam maior prevalência de LER/DORT junto a mulheres (REIS et al., 2000; SALIM, 2003; STRAZDINS; BAMMER, 2004). Entre as potenciais explicaçóes para o afastamento do trabalho entre mulheres acometidas por doenças do trabalho encontram-se problemas relacionados à organização do trabalho, potencializados pelo acúmulo das atividades laborais com as domésticas 
(HENSING; ANDERSSON; BRAGE, 2006). Outro estudo também descreve que a alta prevalência de desordens musculoesqueléticas em mulheres pode estar relacionada às atividades domésticas e de cuidados com familiares, além das características do trabalho (STRAZDINS; BAMMER, 2004).

As patologias englobadas nas siglas LER/DORT representam agravos de difícil obtenção de reconhecimento como doenças causadas pelo trabalho por expressarem distintos interesses conflitantes de classe (CARVALHO et al., 2009). O Instituto Nacional do Seguro Social - INSS aprovou o Nexo Técnico Epidemiológico (NTEP) em 2007, o qual, segundo Vertein e Minayo-Gomes (2000), ao apresentar uma relação da entidade mórbida e das classes da Classificação Nacional de Atividades Econômicas - CNAE, com indicação de doenças e respectivos agentes etiológicos ou riscos ocupacionais, passou para o empregador a necessidade de comprovação de que seu ambiente de trabalho náo causou tal doença ou acidente ao trabalhador. Até março de 2007, o INSS exigia a emissáo da Comunicaçáo de Acidente de Trabalho - CAT para a caracterização das doenças relacionadas ao trabalho (DRT), mas a partir de abril de 2007, o nexo passou também a ser baseado no Nexo Técnico Epidemiológico (SOUZA et al., 2008).

Na Legislação Previdenciária Brasileira, os acidentes de trabalho compreendem as doenças profissionais, doenças do trabalho, acidentes de trajeto, entre outros, e o benefício é concedido ao segurado impedido de trabalhar por doença ou acidente (BRASIL, 2011). Para concessão de auxílio-doença/acidentário é necessária a comprovaçáo da incapacidade em exame realizado pela perícia médica da Previdência Social. Segundo Souza et al. (2008), os benefícios concedidos devido a acidentes e doenças relacionadas ao trabalho são denominados auxílios-doença acidentários (espécie B91); e aqueles devidos a problemas de saúde não relacionados ao trabalho são os auxílios-doença previdenciários (espécie B31).

Transtornos dos tecidos moles podem ser ocasionados por aspectos relacionados ao trabalho, e se enquadrarem em LER/DORT se estabelecido o nexo causal relacionando com o trabalho. $\mathrm{O}$ estabelecimento de nexo causal é fundamental para efeitos de afastamento e recebimento de benefícios, há necessidade de o médico perito do INSS reconhecer o nexo causal e caracterizar as afecçôes como LER/DORT (YENG et al., 2001). Para a avaliaçâo desse quesito (nexo causal), o INSS utiliza, em tese, a avaliação presencial do segurado, o relatório médico e os documentos produzidos pela empresa do pleiteante do benefício por incapacidade, sendo que nos documentos emitidos pelas empresas frequentemente ocorre a descaracterizaçáo do nexo causal entre o quadro clínico (MAENO, 2011).

Existe uma dificuldade para se comprovar o nexo causal da doença, embora existam inúmeras condiçôes desfavoráveis no trabalho que podem estar relacionadas ao aparecimento das LER/DORT nos trabalhadores - apenas $2 \%$ das empresas fazem o registro da Comunicação de Acidente do Trabalho (CAT), dificultando a garantia dos direitos do trabalhador (LEITE; SILVA; MERIGHI, 2007). Atualmente, as doenças predominantes no mundo do trabalho são aquelas que não têm apenas o trabalho como agente causador, ocorrendo frequentemente na populaçáo não trabalhadora ou com causas não ocupacionais, como as LER/DORT, transtornos mentais, entre outras, o que tem gerado conflitos entre empresas, seguradoras e trabalhadores de todo o mundo (SOUZA et al., 2008). Para Almeida e Barbosa-Branco (2011), as doenças osteomusculares estáo mais associadas aos agravos crônicos que agudos, dificultando o estabelecimento de nexo técnico entre agravo e trabalho. Os trabalhadores afastados e adoecidos enfrentam situaçóes adversas, envolvendo dificuldades em ter CAT emitida, em ter sua situação compreendida por gestores e colegas, sendo comum o advento da depressão como consequência de afastamentos prolongados (MAENO, 2011).

O trabalhador que recebe auxílio-doença/acidentário é obrigado a realizar exame médico periódico e, se constatado que não poderá retornar para sua atividade habitual, deverá participar do programa de reabilitaçáo profissional para o exercício de outra atividade, prescrito e custeado pela Previdência Social, sob pena de ter o benefício suspenso (BRASIL, 2012).

A presença de LER/DORT implica em afastamento do trabalho e, nesse contexto, é importante caracterizar o perfil desses trabalhadores para direcionar açóes de prevenção, promoção e reabilitação em saúde. O objetivo deste estudo foi investigar sobre o perfil de sujeitos com transtornos dos tecidos moles atendidos no Centro de Referência em Saúde do Trabalhador - CEREST Santos-SP, no período de janeiro a dezembro de 2010, e os benefícios previdenciários concedidos.

\section{Materiais e métodos}

Este estudo é exploratório, descritivo e quantitativo. Foram analisados prontuários abertos de sujeitos atendidos no período de $1^{\circ}$ de janeiro de 2010 a 31 de dezembro de 2010 no Centro de Referência 
em Saúde do Trabalhador - CEREST Santos-SP. Foram analisados os prontuários, um a um, para levantamento de dados que foram norteados por um roteiro elaborado para registro em planilha Excel contendo: gênero, idade, escolaridade, profissão, diagnósticos clínicos registrados, situação junto ao último emprego (se afastado, ativo, retorno ao trabalho, demitido), entre outros que fossem relevantes ao estudo. As atividades profissionais foram classificadas de acordo com a Classificação Nacional de Atividades Econômicas - CNAE, e os diagnósticos clínicos registrados pelos médicos que atuavam no serviço foram agrupados e categorizados conforme a Classificação Internacional de Doenças - CID-10. Os prontuários em que não constavam os exames clínicos para diagnóstico foram analisados novamente, quatro meses após a primeira coleta de dados, com o intuito de complementar as informaçóes anteriormente obtidas em possíveis casos de retorno dos sujeitos ao serviço.

Posteriormente foram selecionados para este estudo os sujeitos com transtornos dos tecidos moles estabelecidos entre M60 a M79 pela CID-10, bem como também foram registrados diagnósticos relacionados a transtornos mentais. Os dados foram registrados no Programa Microsoft Excel, e posteriormente foi utilizado o sistema estatístico R Development Core Team ${ }^{\circledR}$. Para verificar se existia associação entre as variáveis de interesse foi realizado o Teste Exato de Fisher e análise de correspondência. A análise de correspondência foi realizada para detalhar o comportamento multivariado das variáveis de interesse e a presença de diagnóstico clínico estabelecido para transtornos dos tecidos moles.

O projeto foi aprovado pelo Comitê de Ética em Pesquisa da Universidade Federal de São Paulo - UNIFESP.

\section{Resultados e discussão}

Foram analisados 206 prontuários de sujeitos atendidos no CEREST Santos de janeiro de 2010 à dezembro de 2010. Dos 206 prontuários, 18,0\% ( $\mathrm{n}=37)$ sujeitos tinham diagnósticos estabelecidos entre M60 a M79 (transtornos dos tecidos moles) pela CID-10 e $13,5 \%(\mathrm{n}=28)$ continham queixas de sintomas dolorosos e suspeitas de transtornos dos tecidos moles. Da amostra total ( $\mathrm{n}=206), 135$ prontuários continham a informação de situação de afastamento do trabalho. Houve associação entre a situação de afastamento do trabalho e diagnóstico clínico estabelecido para transtornos dos tecidos moles $(\mathrm{p}=0,032)$ e entre idade inferior a 40 anos e diagnóstico clínico estabelecido para transtornos dos tecidos moles $(p=0,082)$. Em estudo de Reis et al. (2000), a maioria dos pacientes atendidos em ambulatório de doenças profissionais e com LER tinha menos de 40 anos, e Salim (2003) também indicou em estudo uma predominância de casos de LER/DORT na faixa etária de 30 a 39 anos.

Em análise de correspondência foram detectados três padróes gerais de comportamento nos indivíduos do estudo, através dos dados obtidos e demonstrados na Figura 1:

1. Ter diagnóstico clínico entre os transtornos dos tecidos moles, situação de afastamento do trabalho e idade inferior a 40 anos.

2. Não ter diagnóstico definido (com queixas de sintomas dolorosos e suspeitas de transtornos dos tecidos moles) e demissão.

3. Ter queixa náo relacionada aos transtornos dos tecidos moles (identificada na figura e para este estudo como "queixa não LER") e não estar afastado do trabalho.

Um dos aspectos relevantes identificados na análise de correspondência foi o de não terem diagnóstico definido (com queixas de sintomas dolorosos e suspeitas de transtornos dos tecidos moles) e a ocorrência da demissão. Em estudo de Alencar e Ota (2011) foi encontrada a presença de sintomas dolorosos no trabalho até os trabalhadores não suportarem mais e, entre os aspectos envolvidos, o medo de ser demitido. Os resultados demonstram a realidade do risco de demissáo junto aos diagnósticos ainda indefinidos.

O CEREST Santos presta assistência aos trabalhadores com suspeita de doença relacionada ao trabalho ou que sofram com ameaças à sua integridade física ou mental, de qualquer categoria profissional,

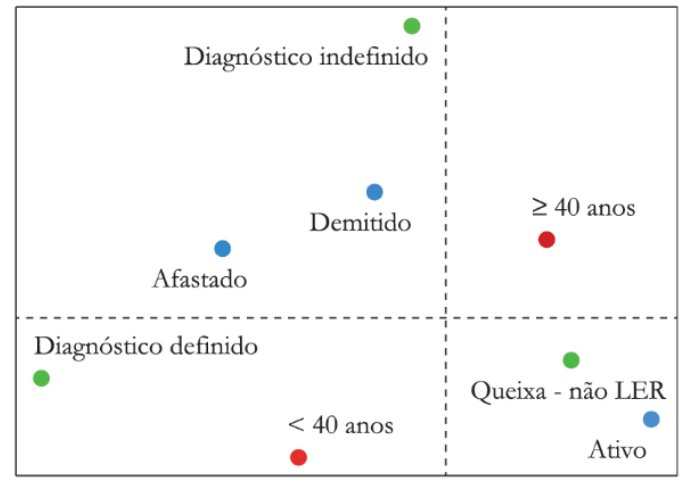

Figura 1. Análise de correspondência para as variáveis: diagnóstico definido ou não, situação de afastamento e idade. 
registrados ou não, servidores públicos, autônomos ou mesmo desempregados que residam em Santos, São Vicente e Praia Grande. A equipe multiprofissional do CEREST realiza açóes de vigilância, assistência e educação em Saúde do Trabalhador.

Alguns dados demográficos dos sujeitos $(n=37)$ com transtornos dos tecidos moles estão descritos na Tabela 1.

Houve predomínio nessa amostra de sujeitos do gênero feminino acometido pelos transtornos dos tecidos moles, $81,1 \%(n=30)$. Segundo Strazdins e Bammer (2004), entre aspectos das condiçóes de trabalho das mulheres encontram-se demandas de trabalho repetitivo, citando como exemplos que $34 \%$ das mulheres, comparadas com $21 \%$ dos homens, ficam sentados na mesma posição por um longo período de tempo; $81 \%$ das mulheres, comparadas a $73 \%$ dos homens, trabalham mais de cinco horas por dia no computador; e 30\% das mulheres, comparadas a 16\% dos homens, referiram desenvolvimento de esforços repetitivos em todo o período de trabalho. É essencial ir além da divisão

Tabela 1. Perfil demográfico dos sujeitos da pesquisa.

\begin{tabular}{llcr}
\hline & Variáveis & $\mathrm{n}$ & \multicolumn{1}{c}{$\%$} \\
\hline Gênero & Feminino & 30 & $81,1 \%$ \\
& Masculino & 7 & $18,9 \%$ \\
& $20-30$ & 2 & $5,5 \%$ \\
& $31-40$ & 13 & $35,1 \%$ \\
\multirow{5}{*}{ Moradia etária } & $41-50$ & 13 & $35,1 \%$ \\
& $51-60$ & 8 & $21,6 \%$ \\
& $61-70$ & 1 & $2,7 \%$ \\
& Guarujá & 1 & $2,7 \%$ \\
Idade & Praia Grande & 6 & $16,2 \%$ \\
& Santos & 26 & $70,3 \%$ \\
& São Vicente & 4 & $10,8 \%$ \\
& Média: 43,$24 ;$ DP: 8,76 & \\
\hline
\end{tabular}

de trabalho para a compreensão da desigualdade na distribuição de LER/DORT entre trabalhadores. Segundo Salim (2003), as condições de precarização de trabalho têm sido mais deletérias à saúde das mulheres. Conforme demonstrado na Tabela 1, a faixa etária mais acometida pelos transtornos dos tecidos moles foi entre 31-50 anos, o que caracteriza que os sujeitos estavam em fase produtiva. Em estudo de Alcântara, Nunes e Ferreira (2011), a faixa etária de maior prevalência de DORT foi entre 40 e 59 anos.

Os prontuários dos sujeitos desse período não continham informação sobre escolaridade, sendo que essa informação atualmente já é obtida no serviço. Segundo Salim (2003), há relevância do nível de escolaridade como elemento de peso na eficácia de açôes preventivas voltadas à minimização dos danos à saúde no ambiente de trabalho.

Os dados referentes às categorias profissionais estão demonstrados na Tabela 2 .

Nesta amostra, de acordo com a Classificação Nacional de Atividades Econômicas (BRASIL, 2004), a atividade que teve maior número de trabalhadores acometidos por transtornos dos tecidos moles foi "outras atividades de serviço", com 33,3\% ( $\mathrm{n}=12)$, as quais englobam as profissôes auxiliar de limpeza e auxiliar de serviços gerais, entre outras. Em segundo lugar, as atividades de serviços financeiros, sendo, da amostra acima $(n=36), 22,2 \%$ do setor bancário $(n=8)$.

Sobre outros dados relacionados ao trabalho obtidos em alguns prontuários, 56,7\% (n=17) estavam trabalhando há cinco anos ou menos na última empresa e 43,3\% (n=13) dos trabalhadores estavam trabalhando há mais de cinco anos na última empresa (amostra total obtida: $n=30$ ). Foi identificado que $60,9 \%(n=14)$ dos sujeitos estavam há cinco anos ou menos na mesma atividade profissional e 39,1\%

Tabela 2. Dados sobre o setor de atividade profissional dos sujeitos.

\begin{tabular}{lcr}
\hline \multicolumn{1}{c}{ Setor/Atividade profissional } & $\mathbf{n}$ & \multicolumn{1}{c}{$\%$} \\
\hline Alimentação & 1 & $2,8 \%$ \\
Atividade de atenção à saúde humana & 3 & $8,3 \%$ \\
Atividade de prestação de serviço de informação & 1 & $2,8 \%$ \\
Atividades de rádio e televisão & 1 & $2,8 \%$ \\
Atividades de serviço financeiro & 8 & $22,2 \%$ \\
Manutenção, recuperação e instalação de máquinas e equipamentos & 2 & $5,6 \%$ \\
Outras atividades de serviço & 12 & $33,3 \%$ \\
Publicidade e pesquisa de mercado & 1 & $2,8 \%$ \\
Serviços de escritório, de apoio administrativo e outros prestados a empresas & 4 & $11,1 \%$ \\
Serviços domésticos & 1 & $2,8 \%$ \\
Transporte & 2 & $5,6 \%$ \\
Total & $36^{*}$ & $100,0 \%$ \\
\hline
\end{tabular}

*Número de dados obtidos ( $\mathrm{n}=36$, pois um prontuário não continha essa informação). 
$(\mathrm{n}=9)$ dos sujeitos, há mais de cinco anos (amostra total obtida: $\mathrm{n}=23$ ).

Em relação às principais queixas dos sujeitos em primeira consulta, essas em geral estavam relacionadas aos sintomas dolorosos. A dor é o principal sintoma da LER, ela é decorrente das alteraçôes morfofuncionais adaptativas dos tecidos quando expostos aos fatores de risco no ambiente laboral (PESSOA; CARDIA; SANTOS, 2010). As principais queixas e se houve mais de uma em consultas iniciais estão demonstrados na Tabela 3.

As principais queixas dos sujeitos estavam relacionadas aos sintomas dolorosos em membros superiores $75,7 \%(n=28)$ e região cervical $16,2 \%(n=6)$. Dentre as doenças osteomusculares relacionadas ao trabalho, as que acometem a regiáo cervical e/ou os membros superiores têm se destacado não só pela frequência com que têm sido diagnosticadas mas também por atingirem indiscriminadamente trabalhadores de diversos ramos de atividade (SOUZA; SANTANA, 2011). Alguns apresentaram mais de uma queixa $24,3 \%(n=9)$, indicando a existência de mais de um agravo.

Houve também queixa inicial relacionada a problema emocional, o que pode estar relacionado ao processo de adoecimento e afastamento, como: medo do desemprego, das consequências do adoecimento, das repercussóes funcionais e relacionais no cotidiano de vida que, entre outros, são aspectos que podem estar presentes. Em estudo de Salermo, Silvestre e Sabino (2011) em levantamentos de prontuários de sujeitos com LER de um CEREST do interior de São Paulo, nas anotações havia queixas de tristeza, crises de choro, medo de retornar ao trabalho, insegurança em relação ao trabalho, insegurança e conflitos na relação familiar.

Os diagnósticos clínicos dos sujeitos estão demonstrados na Tabela 4.

Entre os principais transtornos dos tecidos moles estiveram lesões em região de ombro e braço $(73,0 \%)$ e as sinovites e tenossinovites $(43,2 \%)$. Em estudo realizado por Reis et al. (2000) em ambulatório de doenças ocupacionais de hospital, as sinovites e tenossinovites estavam em terceiro lugar. Também em estudo de Alcântara, Nunes e Ferreira (2011), as sinovites e tenossinovites (M65) estavam entre os diagnósticos mais encontrados. Como a prevalência dos sujeitos deste estudo em relação à categoria profissional englobou as profissóes auxiliar de limpeza e auxiliar de serviços gerais, entre outras, com exigências físicas e de utilização de membro superior na execução de tarefas, talvez se justifique a alta prevalência de lesôes em região de ombros. Lesóes em região de ombro também foram encontradas junto aos bancários. Ainda, foi identificado um número relativamente grande para esta amostra, 62,2\% ( $n=23)$, de sujeitos com mais de um diagnóstico clínico. Além dos diagnósticos clínicos estabelecidos entre transtornos dos tecidos moles foram encontrados diagnósticos relacionados à saúde mental em 13,5\% (n=5) dos sujeitos, como: transtorno misto ansioso e depressivo e transtorno de adaptação.

Dos 37 ( $\mathrm{n}=37$ ) prontuários analisados, somente em 28 ( $\mathrm{n}=28)$ prontuários constava a informação sobre a última situação junto ao emprego. Desses, 64,3\% $(\mathrm{n}=18)$ estavam afastados do trabalho, 21,4\% $(\mathrm{n}=6)$, ativos e $14,3 \%(n=4)$ haviam sido demitidos quando constatada a doença. Dos que estavam afastados do trabalho, $13,5 \%(\mathrm{n}=5)$ recebiam o benefício auxílioacidente (B91) e 10,8\% (n=4), auxílio-doença (B31), não havendo informaçóes junto aos demais sujeitos. Supóe-se que alguns sujeitos tenham se dirigido a outros serviços da rede pública e não retornaram ao centro de referência, o que justificaria a ausência de algumas informaçôes em prontuários, aspecto que necessitaria de maiores investigaçôes. Esse aspecto poderia estar relacionado a vários fatores, desde dificuldades financeiras para o transporte, facilidade

Tabela 3. Principais queixas e se houve mais de uma em consultas iniciais.

\begin{tabular}{lcc}
\hline Queixas em consultas iniciais & $\mathbf{n}$ & $\mathbf{\%}$ \\
\hline Dores em membros superiores & 28 & $75,70 \%$ \\
Cervicalgia & 6 & $16,20 \%$ \\
Lombalgia & 5 & $13,50 \%$ \\
Problemas emocionais & 2 & $5,40 \%$ \\
Outras queixas & 10 & $27,0 \%$ \\
Mais de uma queixa & 13 & $35,1 \%$ \\
\hline
\end{tabular}

Tabela 4. Dados sobre o diagnóstico clínico presentes nos prontuários analisados (período 2010).

\begin{tabular}{lcr}
\hline \multicolumn{1}{c}{ Diagnóstico clínico } & $\mathbf{n}$ & \multicolumn{1}{c}{$\%$} \\
\hline Sinovites e tenossinovites & 16 & $43,23 \%$ \\
Bursite de ombro* & 15 & $40,54 \%$ \\
Síndrome do manguito rotador* & 8 & $21,62 \%$ \\
Lesões em ombro (sem & 3 & $8,11 \%$ \\
especificação)* & & \\
Dedo em gatilho & 2 & $5,40 \%$ \\
Epicondilite & 2 & $5,40 \%$ \\
Tendinite bicipital* & 1 & $2,70 \%$ \\
Tendinite calcificada & 1 & $2,70 \%$ \\
Outros transtornos dos tecidos & 9 & $24,32 \%$ \\
moles & & \\
Outros diagnósticos clínicos & 6 & $16,22 \%$ \\
Mais de um diagnóstico clínico & 23 & $62,16 \%$ \\
\hline
\end{tabular}

*Lesões em região de ombro e braço. 
de atendimento em outros locais mais próximos da residência, outros interesses, entre outros.

Conforme dados obtidos neste estudo, apenas $13,5 \%(n=5)$ conseguiram comprovar nexo causal da doença com o trabalho. Existe uma dificuldade para se comprovar o nexo causal da doença, evidenciada também em outros estudos (LEITE; SILVA; MERIGHI, 2007; ALCÂNTARA; NUNES; FERREIRA, 2011; MAENO, 2011).

\section{Considerações finais}

$\mathrm{Na}$ amostra deste estudo, transtornos dos tecidos moles afetaram trabalhadores de diferentes profissóes, sendo que dessas as mais prevalentes foram aquelas com exigências físicas "reconhecidas" em tarefas de trabalho, em faixa etária produtiva, havendo um predomínio do gênero feminino. $\mathrm{O}$ estudo possibilitou conhecer o perfil do trabalhador acometido por transtornos dos tecidos moles atendidos no centro de referência e identificou entre outros aspectos, a dificuldade do nexo causal com o trabalho, que tende a gerar desgaste e sofrimento.

Sujeitos afastados do trabalho geram um impacto social e custos para sistema de saúde pública e Previdência Social e, portanto, açôes preventivas antes do surgimento ou em início de sintomas osteomusculares devem ser realizadas, no intuito de investigar sobre possíveis necessidades de melhoria em condiçóes e aspectos da organização do trabalho. Uma vez adoecidos, os trabalhadores necessitam de amparo e respeito junto aos processos vivenciados, evitando a "precarização social" junto aos sujeitos afastados do trabalho por LER/DORT. Também necessitam de reabilitação profissional que realmente possa dar conta da complexidade envolvida em intervençôes, necessitando de ações de equipes interdisciplinares e multiprofissionais, além da garantia de um efetivo acompanhamento no retorno ao trabalho junto à empresa. Pesquisas futuras devem continuar a explorar a temática, pela importância e necessidade de melhoria em vários aspectos.

\section{Referências}

ALCÂNTARA, M. A.; NUNES, G. S.; FERREIRA, B. C. M. Distúrbios osteomusculares relacionados ao trabalho: o perfil dos trabalhadores em benefício previdenciário em Diamantina (MG, Brasil). Ciência e Saúde Coletiva, Rio de Janeiro, v. 10, n. 8, p. 3427-3436, 2011.

ALENCAR, M. C. B.; OTA, N. H. O afastamento do trabalho por LER/DORT: repercussóes na saúde mental. Revista de Terapia Ocupacional da Universidade de São Paulo, São Paulo, v. 22, n. 1, p. 60-67, 2011.
ALMEIDA, P. C. A.; BARBOSA-BRANCO, A. Acidentes de trabalho no Brasil: prevalência, duração e despesa previdenciária dos auxílios-doença. Revista Brasileira de Saúde Ocupacional, São Paulo, v. 36, n. 124, p. 195-207, 2011.

BRASIL. Receita Federal. Classificação Nacional de Atividades Econômicas - CNAE. Brasília, 2004. Disponível em: $<$ http://www.cnae.ibge.gov.br/estrutura. asp?TabelaBusca=CNAE_200@CNAE\%202.1>. Acesso em: 2 nov. 2012.

BRASIL. Ministério da Saúde. LER/DORT: protocolos de atenção integrada à saúde do trabalhador de complexidade diferenciada. Brasília, 2006. Disponível em: <http:// bvsms.saude.gov.br/bvs/publicacoes/protocolo_ler_dort. pdf>. Acesso em: 19 out. 2012.

BRASIL. Ministério da Previdência e Assistência Social. Anuário Estatístico da Previdência Social. Brasília, 2011. Disponível em: <http://www.mpas.gov.br/arquivos/ office/1_121023-162858-947.pdf>. Acesso em: 12 out. 2012. BRASIL. Ministério da Previdência Social. Auxílio doença. Brasília. Disponível em: <http://www.previdencia.gov.br/ conteudoDinamico.php?id=21>. Acesso em: 25 out. 2012 .

BUCKLE, P. Ergonomics and musculoskeletal disorders: overview. Occupational Medicine, Guildford, v. 55, n. 3, p. 164-167, 2005.

CARVALHO, M. V. D. et al. LER-DORT: doença do trabalho ou profissional? Revista Gaúch a de Enfermagem, Porto Alegre, v. 30, n. 2, p. 303-310, 2009.

CHIAVEGATO FILHO, L. G.; PEREIRA JUNIOR, A. LER/DORT: multifatorialidade etiológica e modelos explicativos. Interface: Comunicação, Saúde, Educação, Botucatu, v. 8, n. 14, p. 149-162, 2004.

CROOK, J.; MOLDOFSKY, H. Prognostics indicators of disability after a work-related musculoskeletal injury. In: CHALMERS, A. et al. Fibromyalgia, chronic fatigue syndrome, and repetitive strain injury. New York: Haworth Medical Press, 1995. p. 155-159.

GUTTERRES, C. M. F.; BARFKNECHT, K. S. Terapia Ocupacional nas LER/DORT. Boletim da Saúde, Porto Alegre, v. 19, n. 1, p. 85-90, 2005.

HENSING, G.; ANDERSSON, L.; BRAGE, S. Increase in sickness absence with psychiatric diagnosis in Norway: a general population-based epidemiologic study of age, gender and regional distribution. BMC Medicine, Londres, v. 4, n. 19, p. 1-9, 2006.

LEITE, P. C.; SILVA, A.; MERIGHI, M. A. B. A mulher trabalhadora de enfermagem e distúrbios osteomusculares relacionados ao trabalho. Revista da Escola de Enfermagem, São Paulo, v. 41, n. 2, p. 287-291, 2007.

LIN, T. Y. et al. Distúrbios osteomusculares relacionados ao trabalho. Revista Médica, São Paulo, v. 80, n. 2, p. 422-442, 2001.

MAENO, M. LER e transtornos psíquicos relacionados ao trabalho: faces de uma mesma moeda. In: SNELWAR, L. (Org.). Saúde dos bancários. São Paulo: Publisher, 2011. p. 207-223. 
NEVES, I. R. LER: trabalho, exclusão, dor, sofrimento e relação de gênero. Um estudo com trabalhadoras atendidas num serviço público de saúde. Cadernos de Saúde Pública, Rio de Janeiro, v. 22, n. 6, p. 1257-1265, 2006.

PESSOA, J. C. S.; CARDIA, M. C. G.; SANTOS, M. L. C. Análise das limitaçóes, estratégias e perspectivas dos trabalhadores com LER/DORT, participantes do grupo PROFIT-LER: um estudo de caso. Revista Ciência \& Saúde Coletiva, Rio de Janeiro, v. 15, n. 3, p. 821-830, 2010.

REIS, R. J. et al. Perfil da demanda atendida em ambulatório de doenças profissionais e a presença de lesôes por esforços repetitivos. Revista de Saúde Pública, Sáo Paulo, v. 34, n. 3, p. 292-298, 2000.

RIBEIRO, H. P. Lesões por Esforços Repetitivos (LER): uma doença emblemática. Cadernos de Saúde Pública, Rio de Janeiro, v. 13, n. 2, p. 85-93, 1997.

RIO, R. P. LER/DORT: ciência e lei. Novos horizontes da saúde e do trabalho. Belo Horizonte: Health, 1998.

SALERMO, V. L.; SILVESTRE, M. P.; SABINO, M. O. Interfaces LER/Saúde mental: a experiência de um Centro de Referência em Saúde do Trabalhador do Estado de São Paulo. Revista Brasileira de Saúde Ocupacional, São Paulo, v. 36, n. 123, p. 128-138, 2011.
SALIM, C. A. Doenças do trabalho: exclusão, segregação e relaçóes de gênero. São Paulo em Perspectiva, São Paulo, v. 17, n. 1, p. 11-24, 2003.

SOUZA, N. S. S. et al. Doenças do trabalho e benefícios previdenciários relacionados à saúde, Bahia, 2000. Revista de Saúde Pública, São Paulo, v. 42, n. 4, p. 630-638, 2008. SOUZA, N. S. S.; SANTANA, V. S. Incidência de doenças musculoesqueléticas incapacitantes. Cadernos de Saúde Pública, Rio de Janeiro, v. 27, n. 11, p. 2124-2134, 2011. STRAZDINS, L.; BAMMER, G. Women, work and musculoskeletal health. Social Science \& Medicine, New York, v. 58, n. 6, p. 997-1005, 2004.

VERTEIN, M. A. R.; MINAYO-GOMES, C. A construção do "sujeito-doente" em LER. História, Ciência e Saúde-Manguinhos, Rio de Janeiro, v. 7, n. 2, p. 329-347, 2000.

WADELL, G. Preventing incapacity in people with musculoskeletal disorders. British Medical Bulletin, Londres, v. 77-78, p. 55-69, 2006.

YENG, L. T. et al. Distúrbios osteomusculares relacionados ao trabalho. Revista Médica, São Paulo, v. 80, ed. esp. pt 2, p. 422-442, 2001.

\section{Contribuição dos Autores}

Maria do Carmo Baracho de Alencar coordenou a pesquisa, acompanhando a obtenção dos dados, participando de sua análise, discussão e interpretaçáo, além da elaboraçáo e da revisão do texto. Camila de Freitas participou do projeto, da obtenção, análise e discussão dos dados, além da elaboração e da revisão do texto. Lucy Vitale Lopes colaborou na obtenção dos dados e participou de sua discussão e da revisão do texto. Felipe Granado Souza participou da análise dos dados e da revisão do texto. Todos os autores aprovaram a versão final do texto.

\section{Notas}

${ }^{1}$ Apoio: Fundação de Amparo à Pesquisa do Estado de São Paulo - Fapesp. 